\title{
Hyperhomocysteinemia among Omani autistic children: a case-control study
}

\author{
Amanat Ali ${ }^{\bowtie}$, Mostafa I. Waly¹, Yahya M. Al-Farsi², Musthafa M. Essa, \\ Marwan M. Al-Sharbati ${ }^{3}$ and Richard C. Deth ${ }^{4}$ \\ 1Department of Food Science and Nutrition, College of Agricultural and Marine Sciences, Sultan Qaboos University, Oman; ${ }^{2} F a m i l y ~ M e d i c i n e$ \\ and Public Health Department, College of Medicine and Health Sciences, Sultan Qaboos University, Oman; 3Behavioural Medicine Department, \\ College of Medicine and Health Sciences, Sultan Qaboos University, Oman; 4Pharmacology Department, Bouve College of Health Sciences, \\ Northeastern University, Boston, MA 02115, USA
}

High serum homocysteine (Hcy) level is regarded as an indicator for impairment of folate-dependent methionine cycle and is associated with oxidative stress. In a case control study, we evaluated eighty 3-5 years old Omani children (40 diagnosed with Autism Spectrum Disorder and 40 their age and gender matched controls) for their fasting serum homocysteine levels as a biomarker of Autism Spectrum Disorder (ASD). Serum folate and vitamin $B_{12}$ status were also evaluated. The serum homocysteine was measured using an enzyme immunoassay (EIA) technique whereas folate and vitamin $B_{12}$ were measured using an automated random access immune-assay system. The results indicated that mean serum Hcy levels were significantly $(P<0.05)$ higher in autistic children $(20.1 \pm 3.3 \mu \mathrm{mol} / \mathrm{L})$ as compared to controls $(9.64 \pm 2.1 \mu \mathrm{mol} / \mathrm{L})$. Significantly $(P<0.05)$ lower serum folate $(1.8 \pm 0.4 \mu \mathrm{g} / \mathrm{L})$ and vitamin $B_{12}(191.1 \pm 0.9 \mathrm{pg} / \mathrm{mL})$ levels were observed in autistic children as compared to controls $(6.1 \pm 0.6 \mu \mathrm{g} / \mathrm{L}$ and $288.9 \pm 1.3 \mathrm{pg} / \mathrm{mL}$, respectively). The levels of homocysteine in autistic children were also much higher as compared to normal reference values $(5-15 \mu \mathrm{mol} / \mathrm{L})$. The results suggest that high fasting serum homocysteine and low folate and vitamin $B_{12}$ levels could be used as clinical biomarkers for an early diagnosis and management of ASD.

Keywords: serum homocysteine, folate, vitamin $\mathrm{B}_{12}$, autistic children, Oman

Received: 10 May, 2011; revised: 25 November, 2011; accepted:

11 December, 2011; available on-line: 20 December, 2011

\section{INTRODUCTION}

Autistic spectrum disorder (ASD) is a complex and mysterious neurodevelopmental disorder that appears in the early years of life (Santangelo \& Tsatsanis, 2005; Keller \& Persico, 2007; Blaylock, 2008). Autistic children are characterized by impaired social interaction and communication and fail to respond to certain stimuli exhibiting some restricted and repetitive behavior or actions (Reading, 2008; Buehler, 2011). The incidence of autism has increased rapidly in recent decades and the pattern of increase is not influenced by maternal age, race/ethnicity or child gender (Weiser et al., 2008; Towle et al., 2009). The data from the USA and other Western countries indicates the prevalence of autism spectrum disorder of 1 in 110 children (Towle et al., 2009; Daniels et al., 2011). Very limited published data is available about the prevalence of autism spectrum disorder in Omani children. A latest study has reported a total of 113 cases of ASD in Oman indicating an overall prevalence of only 1.4 cases per 10000 children aged $0-14$ years (AlFarsi et al., 2011). The low prevalence has been attributed to under reporting or lack of diagnosis. The parent's report of a child's professional ASD diagnosis has been considered as the most vital piece of information (Daniel et al., 2011).

A number of factors such as genetic, environmental, autoimmune function, redox potential, oxidative stress, and inflammatory biomarkers have been implicated in the etiology of ASD (Reading, 2008; Weiser et al., 2008) that is, however, still poorly understood. The recent rise in autism cases cannot only be explained from genetic causes and therefore certain environmental factors may likely be associated with ASD (Bernard et al., 2002; Adams et al., 2009; Blaylock, 2008; 2009a, 2009b; Kern et al., 2010). Although metabolic abnormalities have been implicated in the pathogenesis of many neurological disorders, the metabolic pathology of autism has been less explored as compared to broad-scale genomic approaches (Miller, 2003; Muntjjewerff et al., 2003). Abnormalities involving the folate-dependent homocysteine methylation reactions, oxidative stress, and genetic predisposition have been implicated as potential causes. It has also been proposed that pro-inflammatory cytokines arising from maternal inflammation, infection and possibly from autoimmunity after passing through the placental and blood-brain barriers may cause aberrant neuronal growth and plasticity within the fetal brain via a "cytokine-storm" (Buehler, 2011). However, the underlying mechanism or a specific metabolic target relevant to ASD has not yet been identified. Clinical biomarkers are of great significance in establishing the diagnosis of many diseases. Identification of the metabolic profile of ASD may therefore represent an effective tool for its early diagnosis and treatment.

Homocysteine (Hcy) is a sulfur-containing amino acid that is known to be implicated in the pathogenesis of many clinical conditions (Newton et al., 2010). Homocysteine in the body is derived from demethylation of

e-mail: amanat@squ.edu.om

Abbreviations: AD, Alzheimer disease; APA, American Psychiatric Association; ASD, autism spectrum disorder; CARS, childhood autism rating scale; CVD, cardiovascular diseases; DS-IV-TR, Diagnostic and Statistical Manual of Mental Disorders, fourth edition, text revision; EIA, enzyme immunoassay; Hcy, homocysteine; GSH, glutathione; MTHFR, methylenetetrahydrofolate reductase; MTHFR C677T, methylenetetrahydrofolate reductase allele variant; SOD, superoxide dismutase; SQUH, Sultan Qaboos University Hospital; tHcy, plasma total homocysteine. 
exogenous methionine and is metabolized along two pathways, remethylation to methionine or transsulfuration to cysteine (Miller \& Kelly, 1996; Miller, 2003; James et al., 2004). Folate and vitamins $B_{6}$ and $B_{12}$ also play an important role in homocysteine metabolism and any defect in these pathways can lead to accumulation of homocysteine in the body (Herrmann et al., 2007). Since one source of Hcy is S-adenosylmethionine, the methyl group donor for DNA-methylation, the use of DNAmethylation based biomarkers may therefore be possible for detection, diagnosis, prediction of response to therapy and prognosis of outcomes for various diseases, including neurodegenerative and psychiatric disorders (Levenson, 2010). The role of homocysteine as a potential and predictive biomarker in age-related neurodegenerative diseases has been well recognized. Increased concentration of total plasma homocysteine is now considered a candidate risk factor for dementia that can predict Alzheimer's disease (AD) or dementia several years before their manifestation (Hermann and Obeid, 2011). Kaluzna-Czaplinska et al. (2011a) reported higher levels of homocysteine $(2.36 \pm 1.24 \mathrm{mmol} / \mathrm{mole}$ creatinine $)$ in the urine of autistic children as compared to their age matched healthy children $(0.76 \pm 0.31 \mathrm{mmol} / \mathrm{mole}$ creatinine). Higher levels of homocysteine have also been reported in the serum and plasma of autistic children (James et al., 2004; Pasca et al., 2006). No such biochemical data is available for normal and autistic children in the Sultanate of Oman. The present study was therefore conducted to compare the serum homocysteine, folate and vitamin $\mathrm{B}_{12}$ levels in normal and autistic Omani children.

\section{MATERIALS AND METHODS}

Study design. This is a case-control study designed to determine the serum Hcy, folate and vitamin $\mathrm{B}_{12}$ levels in normal and autistic Omani children. The study was conducted over the period from December 2009 to August 2010. A total of eighty children (40 confirmed autism spectrum disorder (ASD) cases and 40 their age and gender matched control subjects) participated in this study. Ascertainment of ASD diagnosis was made according to the criteria of the American Psychiatric Association, Diagnostic and Statistical Manual of Mental Disorders, Fourth Edition, Text Revision (DSM-IV-TR) (APA, 2000). All subjects diagnosed with ASD exhibited symptoms within the typical triad of autistic traits: communication impairment, social deficits, and ritualistic interests. Clinical DSM-IV-TR consensus diagnosis was corroborated using the Childhood Autism Rating Scale (CARS). All enrolled cases in this study were newly diagnosed with ASD. This was done to avoid any casual-relationship between the effect of medications on the measured biochemical parameters (Hcy, $\mathrm{B}_{12}$ and folate). All ASD cases were examined by a family physician and a child psychiatrist, who were well trained and experienced in clinical management of ASD. The control subjects were randomly selected from the eligible outpatients at the Department of Child Health at Sultan Qaboos University Hospital (SQUH). All the eligible control subjects were defined as children 3-5 years old who were not known to be autistic or to have any other neurodevelopmental or behavioral disturbances that could be related to or confused with ASD. In order to exclude the possibility that the controls could have any sub-clinical autistic features, each control subject was also clinically examined by the family physician and pediatrician.
The study was approved by the Medical Research Ethics Committee of Sultan Qaboos University.

Serum homocysteine (Hcy), folate and vitamin $\mathbf{B}_{12}$ measurements. Fasting blood samples were collected from both the cases and controls at 8:00 am during their visit to the hospital in the outpatient department. Ten $\mathrm{ml}$ of venous blood was collected from the median cubital vein by venipuncture into a plain tube. Following centrifugation, the serum was transferred to an Eppendorf tube and stored at $-80^{\circ} \mathrm{C}$ prior to Hcy measurements. The serum homocysteine was measured using an enzyme immunoassay (EIA) technique using an Immulite 2000 homocysteine analyzer (Quillard et al., 2003). The principle of the procedure is based on competitive immunoassay. Normal fasting serum Hcy reference values reported in the literature are $5-15 \mu \mathrm{mol} / \mathrm{L}$ (Frantzen et al., 1998). Serum folate and vitamin $B_{12}$ were measured using an automated random-access immunoassay system (Siemens Medical Solution Diagnostics, ADVIA Centaur Chemistry Analyzer, Bohemia, NY 11716, USA).

Statistical analysis. The data was analyzed statistically using GraphPad Prism statistical software package for personal computers version 5. Results are presented as means \pm standard deviation (S.D.). Student's unpaired t-test was used to compare the values in normal and autistic Omani children. The level of statistical significance was set at $P<0.05$ (Snedecor \& Cochran, 1989).

\section{RESULTS AND DISCUSSION}

The results on the serum homocysteine levels in both autistic Omani children and their age-matched healthy controls are presented in Fig. 1. The results indicated that the mean serum Hcy levels were significantly $(P<0.01)$ higher in autistic children $(20.1 \pm 3.3 \mu \mathrm{mol} / \mathrm{L})$ as compared to their age and gender matched healthy controls $(9.64 \pm 2.1 \mu \mathrm{mol} / \mathrm{L})$. The level of serum homocysteine in Omani autistic children observed in this study was also much higher than the reported normal reference values (5-15 $\mu \mathrm{mol} / \mathrm{L})$ (Frantzen et al., 1998). The results of the present study are in line with the previously reported data of Pasca et al. (2006) who observed significantly higher levels of plasma homocysteine in autistic children $(9.83 \pm 2.75 \mu \mathrm{mol} / \mathrm{L})$ as compared to normal healthy children $(7.51 \pm 0.93 \mu \mathrm{mol} / \mathrm{L})$. Some other studies have also reported higher levels of homocysteine in the serum and plasma of autistic children (Boris et al.,

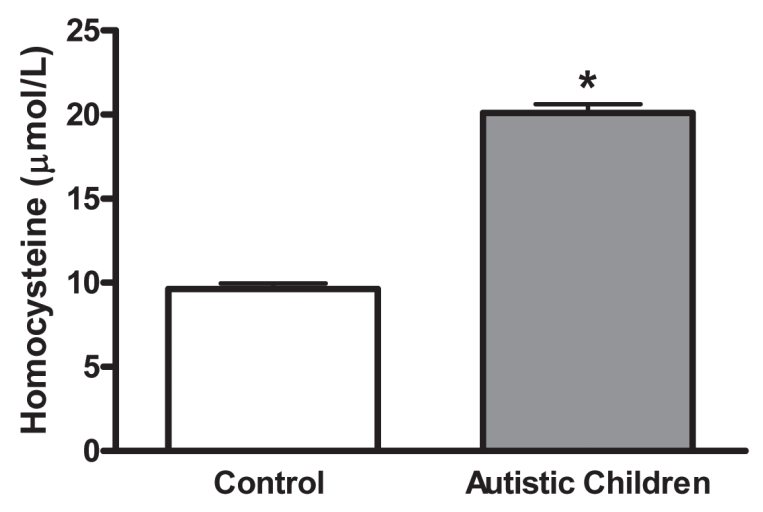

Figure 1. Serum homocysteine levels in control and autistic children.

*Significantly higher in autistic children as compared to controls $(P<0.05)$. 


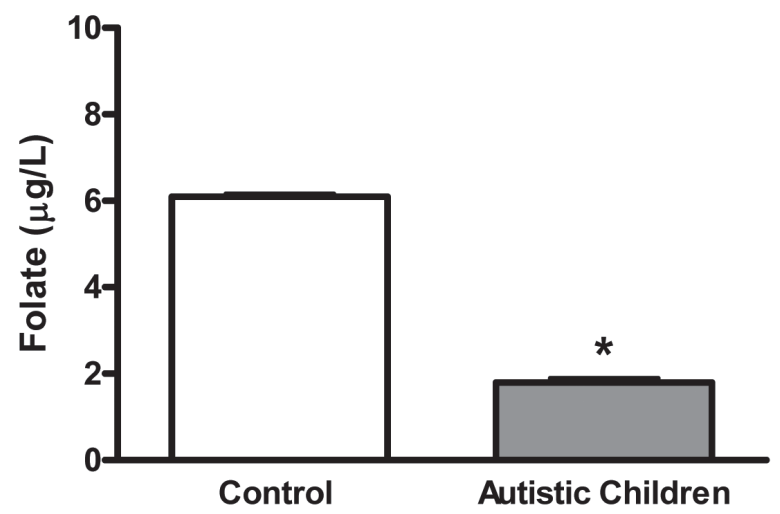

Figure 2. Serum folate levels in autistic children as compared to controls.

${ }^{*}$ Significantly lower in autistic children as compared to controls $(P<0.05)$.

2004; James et al., 2004; Waly et al., 2004; Moretti et al., 2005), which suggests that hyperhomocysteinemia could be present in children with ASD. Higher levels of homocysteine have also been reported in the urine of autistic children as compared to their age and gender matched healthy controls (Kaluzna-Czaplinska et al., 2011a).

It has been suggested that the elevated serum levels of Hcy can be both due to genetic as well as nutritional factors (Dhonukshe-Rutten et al., 2009; Wijsman et al., 2011). In the body, homocysteine (Hcy) is derived from demethylation of exogenous methionine (Miller \& Kelly, 1996; Miller, 2003). Methionine synthase is responsible for recycling the toxic levels of homocysteine into methionine. Methylenetetrahydrofolate reductase (MTHFR) is the central enzyme in folate metabolism and acts at the crossroads between methyl group transfer and biosynthesis of nucleotides. Any reduction in its concentration may affect DNA synthesis (Ryan \& Weir, 2001; James et al., 2008). Decreased methionine synthase activity and increased frequency of methylenetetrahydrofolate reductase allele variant (MTHFR C677T) can favour increased levels of plasma homocysteine (James et al., 2008; Pasca et al., 2008). Studies have, however, shown that MTHFR C677T alone is not a risk factor for ASD (Santos et al., 2010). High levels of plasma homocysteine and increased oxidative stress have generally been associated in the pathophysiology of many neuropsychiatric disorders

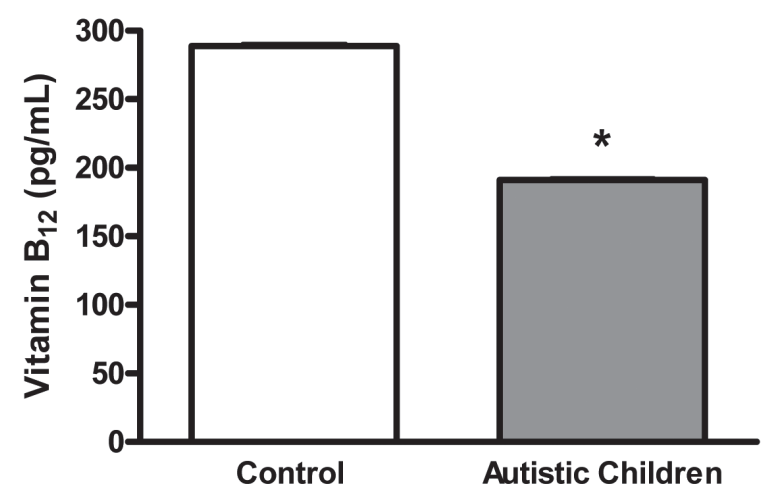

Figure 3. Serum vitamin B12 levels in autistic children as compared to controls.

"Significantly lower in autistic children as compared to controls $(P<0.05)$. including ASD (Chauhan \& Chauhan 2006; Suh et al., 2008; Ientile et al., 2010; Tu et al., 2010). Homocysteine and especially its metabolic products are powerful excito-toxins, which can reduce energy production by mitochondria and may greatly enhance the excito-toxicity of many environmental neurotoxins such as mercury, lead, cadmium, aluminum, fluoride, etc. (Blaylock, 2009a).

The results on the serum folate and vitamin $B_{12}$ levels in Omani autistic and normal children are shown in Figs. 2 and 3. Significantly $(P<0.05)$ lower serum folate $(1.8 \pm 0.4 \mu \mathrm{g} / \mathrm{L})$ and vitamin $B_{12}(191.1 \pm 0.9 \mathrm{pg} / \mathrm{mL})$ levels were observed in autistic children as compared to controls $(6.1 \pm 0.6 \mu \mathrm{g} / \mathrm{L}$ and $288.9 \pm 1.3 \mathrm{pg} / \mathrm{mL}$ respectively). The serum concentrations of folate and Vitamin $\mathrm{B}_{12}$ in autistic children were much below the values defined as deficient levels $(3.0 \mu \mathrm{g} / \mathrm{L}$ and $<250 \mathrm{pg} / \mathrm{ml}$ respectively) for these nutrients (Shils et al., 2006). Our results, however, are not in agreement with the previously reported data by Pasca et al. (2008) who did not show any difference in serum folate levels between ASD patients and their control samples. Folate and vitamins $\mathrm{B}_{6}$ and $\mathrm{B}_{12}$ play an important role in the metabolism of homocysteine and any defect in Hcy turnover due to either dietary deficiencies or mal-absorption or inappropriate metabolic utilization of these nutrients can lead to accumulation of homocysteine in the body (James et al., 2008; Herrmann et al., 2007). It has therefore been hypothesized that higher homocysteine level should not only be considered as a mere marker of vitamin deficiency but also as a risk factor or an indicator of disease (Ientile et al., 2010). The use of DNA-methylation-based biomarkers has also been proposed for detection, diagnosis, prediction of response to therapy and prognosis of outcomes for various diseases, including neurodegenerative and psychiatric disorders (Levenson, 2010).

Many children with ASD show selective food choices (Ahearn et al., 2001; Paul et al., 2007) that could cause vitamin deficiencies because of improper diet (Kaluzna-Czaplinska et al., 2009) resulting in aggravation of some autistic symptoms. Saudi autistic children showed impaired energy metabolism that was correlated with oxidative stress, which was reported to occur due to glutathione (GSH) depletion and over-expression of superoxide dismutase (SOD) activity in these children (AlMosalem et al., 2009; Al-Gadani et al., 2009). Waskiewicz et al. (2010) observed an inverse association between the consumption of vitamins $\mathrm{B}_{6}, \mathrm{~B}_{12}$ and folate and Hcy concentration and prevalence of hyperhomocysteinemia in Polish population. Supplementary intake of vitamins $\mathrm{B}_{6}, \mathrm{~B}_{12}$ and folate were effective in lowering the urinary homocysteine levels (Kaluzna-Czaplinska et al., 2011b). Xia (2011) reported that a 9-year-old boy with autism responded positively to nutritional supplements. A role and efficacy of nutritional supplements in autism-spectrum disorders has been suggested (James et al., 2009; $\mathrm{Xia}, 2011)$. In autistic children a specific diet is therefore considered of great significance.

Data from various studies suggests a relationship between high levels of Hcy and an increased risk of CVD, thrombosis, stroke and neurodegenerative diseases (Hoțoleanu et al., 2007; Humphrey et al., 2008; Lubinska et al., 2006; Tu et al., 2010; Hermann \& Obeid, 2011; Remacha et al., 2011). Plasma total homocysteine (tHcy) levels could also be associated with rapid cognitive decline and higher behavioral disturbances and depression in Alzheimer disease (Seshadri et al., 2002; Chen et al., 2010; Tu et al., 2010). Plasma Hcy level has already been recognized as a potential and predictive biomarker 
in age-related neurodegenerative diseases (Hermann \& Obeid, 2011). Altered plasma fatty acid pattern in Saudi autistic patients has also been proposed as a diagnostic biomarker for autism (El-Ansary et al., 2011). The results of our study are the first of its kind reported from Oman and confirm the hypothesis that increased serum levels of homocysteine could be implicated in the pathophysiology of ASD in Omani children. The lower serum folate and vitamin $\mathrm{B}_{12}$ levels observed in Omani autistic children also need further attention to explain their role in the complex etiology of ASD. The serum homocysteine, folate and vitamin $\mathrm{B}_{12}$ levels can therefore be used as clinical biomarkers not only for diagnosing the possible nutritional deficiencies but also to identify alterations in metabolic pathways. The outcome of this study suggests role of homocysteine as a potential biomarker in the progression and early detection of autism in the Sultanate of Oman. Further studies with larger cohort are required to validate these preliminary results.

\section{CONCLUSIONS}

The results of our study confirm the hypothesis that increased levels of fasting serum homocysteine, and lower levels of folate and vitamin $\mathrm{B}_{12}$ could be implicated in the pathophysiology of ASD and may be used as clinical biomarkers for an early diagnosis and management of Omani autistic children.

\section{Acknowledgements}

The financial assistance provided by Sultan Qaboos University under an internal grant (IG/AGR/ FOOD/10/01) is greatly acknowledged. We would also like to thank the SQU Hospital staff and the parents of autistic as well as the normal children for their cooperation during this study.

\section{REFERENCES}

Adams JB, Baral M, Geis E, Mitchel JL, Ingram J, Hensley A, Zappia I, Newmark S, Gehn E, Rubin RA, Mitchel K, Bradstreet J, El-Dahr JJM (2009) The severity of autism is associated with toxic metal body burden and red blood cell glutathione levels. J Toxicol 2009: Article ID 532640, 7 pages, Doi:10.1155/2009/532640.

Ahearn WH, Castine T, Nault K, Green G (2001) An assessment of food acceptance in children with autism or pervasive developmental disorder not otherwise specified. I Autism Dev Disord 31: 505-511.

Al-Farsi MY, Al-Sharbati MM, Al-Farsi AO, Al-Shafaee SM, Brooks RD, Waly IM (2011) Brief Report: Prevalence of Autistic Spectrum Disorders in the Sultanate of Oman. J Autism Dev Disord. 41: 821825.

Al-Gadani Y, El-Ansary A, Attas O, Al-Ayadhi L (2009) Metabolic biomarkers related to oxidative stress in Saudi autistic children. Clinical Biochem 42: 1032-1040.

Al-Mosalem OA, El-Ansary A, Attas O, Al-Ayadhi L (2009) Metabolic biomarkers related to energy metabolism in in Saudi autistic children. Clinical Bichem 42: 949-957.

American Psychiatric Association, APA (2000) Diagnostic criteria for autistic disorder. In: Diagnostic and statistical manual of maternal disorders (Fourth Edition text revision (DSM-IV-TR). American Psychiatric Association, Washington, DC, USA, pp. 75.

Bernard S, Enayati A, Roger H, Binstock T, Redwood L (2002) The role of mercury in the pathogenesis of autism. Mol Psychiat 7: S42S43.

Blaylock RL (2008) A possible central mechanism in autism spectrum disorders, part 1. Altern Ther Health Med 14: 46-53.

Blaylock RL (2009a) A possible central mechanism in autism spectrum disorders, part 2. immunoexcitotoxicity. Altern Ther Health Med 14: 60-67.

Blaylock RL (2009b) A possible central mechanism in autism spectrum disorders, part 3: the role of excitotoxin food additives and the synergistic effects of other environmental toxins. Altern Ther Health Med 14: 56-60.
Boris M, Goldblatt A, Galanko J, James JM (2004) Association of MTHFR Gene Variants with Autism. J Am Phys Surg 1: 106-108.

Buehler MR (2011) A proposed mechanism for autism: an aberrant neuroimmune response manifested as a psychiatric disorder. Med Hypotheses [Epub ahead of print].

Chauhan A, Chauhan V (2006) Oxidative stress in autism. Pathophysiology 13: 171-181.

Chen CS, Chou MC, Yeh YC, Yang YH, Lai CL, Yen CF, Liu CK, Liao YC (2010) Plasma homocysteine levels and major depressive disorders in Alzheimer disease. Am J Geriatr Psychiatry. 18: 10451048.

Daniels AM, Rosenberg RE, Anderson C, Law JK, Marvin AR, Law PA (2011) Verification of Parent-Report of Child Autism Spectrum Disorder Diagnosis to a Web-Based Autism Registry. J Autism Dev Disord. DOI.10.1007/s10803-011-1236-7.

Dhonukshe-Rutten RAM, de Vries, JHM, de Bree A, van der Put N, van Staveren WA, de Groot LCPGM (2009) Dietary intake and status of folate and vitamin $\mathrm{B}_{12}$ and their association with homocysteine and cardiovascular disease in European populations. Eur J Clin Nut 63: 18-30

El-Ansary A, Bacha ABG, Al-Ayadhi L (2011) Plasma fatty acids as diagnostic markers in autistic patients from Saudi. Lipids Health Disease 10: 62. doi:10.1186/1476-511X-10-62.

Frantzen F, Faaren AL, Alfheim I, Nordhei AK (1998) Enzyme conversion immunoassay for determining total homocysteine in plasma or serum. Clin Chem 44: 311-316.

Herrmann W, Herrmann M, Obeid R (2007) Hyperhomocystenemia: a critical review of old and new aspects. Curr Drug Metab 8: 17-31.

Herrmann W, Obeid R (2011) Homocysteine: a biomarker in neurodegenerative diseases. Clin Chem Lab Med 49: 435-441.

Hoțoleanu C, Porojan-Iuga M, Rusu ML, Andercou A (2007) Hyperhomocysteinemia: clinical and therapeutical involvement in venous thrombosis. Rom J Intern Med 45: 159-64.

HumphreyLL, Fu R, Roger K, Freeman M, Helfand M (2008) Homocysteine level and coronary heart disease incidence: a systematic review and meta-analysis. Mayo Clin Proc 83: 1203-1212.

Ientile R, Curro' M, Ferlazzo N, Condello S, Caccamo D, Pisani F (2010) Homocysteine, vitamin determinants and neurological diseases. Front Biosci 2: 359-372.

James SJ, Cutler P, Melnyk S, Jernigan S, Janak L, Gaylor DW, Neubrander JA (2004). Metabolic biomarkers of increased oxidative stress and impaired methylation capacity in children with autism $A m$ I Clin Nutr 80: 1611-1617.

James SJ, Melnyk S, Jernigan S, Hubanks A, Rose S, Gaylor DW (2008). Abnormal transmethylation/transsulfuration metabolism and DNA hypomethylation among parents of children with autism. J Autism Dev Disord 31: 1976.

James SJ, Melnyk S, Fuchs G, Reid T, Jernigan S, Pavliv O, Hubanks A, Gaylor DW (2009) Efficacy of methylcobalamin and folinic acid treatment on glutathione redox status in children with autism. Am J Clin Nutr 89: 425-30.

Kaluzna-Czaplinska J, Michalska M, Socha E, Blaszczyk S, RozettiSzymariska A, Rynkowski J (2009) Nutritional deficiencies in children for example of autistic children. Nowa Padiatria 4: 94-100.

Kaluzna-Czaplinska J, Michalska M, Rynkowski J (2011a) Homocysteine level in urine of autistic and healthy children. Acta Biochim Polon 58: 31-34.

Kaluzna-Czaplinska J, Michalska M, Rynkowski J (2011b) Vitamin supplementation reduces the levels of homocysteine in the urine of autistic children. Nutr Res 31: 318-321.

Keller F, Persico AM (2007) The neurobiological context of autism. Mol Neurobiol 28: 1-22.

Kern JK, Geier DA, Adams JB, Geier MR (2010) A biomarker of mercury body-burden correlated with diagnostic domain specific clinical symptoms of autism specrum disorder. Biometals 23: 1043-1051.

Levenson VV (2010) DNA methylation as a universal biomarker. Exp Rev Mol Diagn 10: 481-488.

Lubinska M, Kazimierska E, Sworczak K (2006) Hyperhomocysteinemia as a new risk factor for different disease. Adv Clin Exp Med 15: 897-903.

Miller AM, Kelly GS (1996) Methionine and homocysteine metabolism and the nutritional prevention of certain birth defects and complications of pregnancy. Altern Med Rev 4: 220-235.

Miller AL (2003)The methionine-homocysteine cycle and its effects on cognitive diseases. Altern Med Rev 8: 7-19.

Moretti P, Sahoo T, Hyland K, Bottiglieri T, Peters S, del Gaudio D, Roa B, Curry S, Zhu H, Finnell RH, Neul JL, Ramaekers VT, Blau N, Bacino CA, Miller G, Scaglia F (2005) Cerebral folate deficiency with developmental delay, autism, and response to folinic acid. Neurology 6: 1088-1090

Muntjjewerff JW, Van der Put N, Eskes T (2003) Homocysteine metabolism and B-viatmins in schizophrenic patients: low plasma folate as a possible independent risk factor for schizophrenia. Psychiatry Res 121: 1-9. 
Newton LA, Sandhu K, Livingstone C, Leslie R, Davis J. (2010) Clinical diagnostics for homocysteine: a rogue amino acid? Expert Rev Mol Diagn 10: 489-500.

Paşca SP, Nemeş B, Vlase L, Gagyi CE, Dronca E, Miu AC, Dronca M (2006) High levels of homocysteine and low serum paraoxonase 1 arylesterase activity in children with autism. Life Sci 78: 2244 2248 .

Paşca SP, Dronca E, Kaucsar T, Craciun EC, Endreffy E, Ferencz BK (2008). One carbon metabolism disturbances and C677T MTHFR gene polymorphism in children with autism spectrum disorders. $J$ Cell Mol Med 13: 4229-4238.

Paul C, William KE, Riegel K, Gibbons B (2007) Combining repeated taste exposure and escape prevention: an intervention for the treatment of extreme food selectivity. Appetite 49: 708-711.

Quillard M, Berthe MC, Sauger F, Lavoinne A (2003) Plasma determination of homocysteine on CPC Immulite 2000: comparison with determination on IMX Abbott. Ann Biol Clin 61: 699-704.

Reading R (2008) Autism spectrum disorders: clinical and research frontiers. Child Care Health Dev. 34: 697-708.

Remacha AF, Souto JC, Piñana JL, Sardà MP, Queraltó JM, Martí-Fabregas J, García-Moll X, Férnandez C, Rodriguez A, Cuesta J (2011) Vitamin B12 deficiency, hyperhomocysteinemia and thrombosis: a case and control study. Int J Hematol 93: 458-64.

Ryan BM, Weir DG (2001) relevance of folate metabolism in the pathogenesis of colorectal cancer. I lab Clin Med 138: 164-176.

Santangelo SL, Tsatsanis K (2005) What is known about autism: genes, brain, and behavior? Am J Pharmacogenomics 5: 71-92.

Santos PAC, Longo D, Brandalize APC, Schueller-Faccini L (2010) MTHFR C677T is not a risk factor for autism spectrum disorders in South Brazil. Psychiatric Gen 20: 187-189.

Seshadri S, Beiser A, Selhub J, Jacques PF, Rosenberg IH, D’Agostino RB, Wilson PW, Wolf PA (2002) Plasma homocysteine as a risk factor for dementia and Alzheimer's disease. $N$ Engl J Med 346: 476-483.

Shils ME, Shike M, Ross AC, Caballero B, Cousins RJ (2006) Modern Nutrition in Health and Disease, 10th edn, pp 550-552. Lippincott Williams \& Wilkins, A Wolter Kulwer Company, Baltimore, Maryland, USA.
Snedecor G, Cochran G (1989) Statistical Methods, 8th ed, Iowa State University Press, Iowa, USA.

Suh JH, Walsh WJ, McGinnis WR, Lewis A, Ames BN (2008) Altered sulfur amino acid metabolism in immune cells of children diagnosed with autism. Am J Biochem Biotech 4: 105-113.

Towle PO, Visintainer PF, O’Sullivan C, Bryant NE, Busby S (2009) Detecting autism spectrum disorder from early intervention charts: methodology and preliminary findings. J Autism Dev Disord 39: 444 452.

Tu MC, Huang CW, Chen NC, Chang WN, Lui CC, Chen CF, Chen C, Wang YL, Lin YT, Chang CC (2010) Hyperhomocysteinemia in Alzheimer dementia patients and cognitive decline after 6 months follow-up period. Acta Neurol Taiwan 19:168-177.

Waly M, Olteanu H, Banerjee R, Choi SW, Mason JB, Parker BS, Sukumar S, Shim S, Sharma A, BenzecryJM, Power-Charnitsky VA, Deth RC (2004) Activation of methionine synthase by insulin-like growth factor-1 and dopamine: a target for neurodevelopmental toxins and thimerosal. Mol Psychiatry 9: 358-370.

Waskiewicz, A., E. Sygnowska, G. Broda. 2010. Dietary intake of vitamin B6, B12 and folate in relation to homocysteine serum concentration in the adult Polish population - WOBASZ Project. Kardiol Pol 68: 275-282.

Weiser M, Reichenberg A, Werbeloff N, Kleinhaus K, Lubin G, Shmushkevitck M, Caspi A, Malaspina D, Davidson M (2008) Advanced parental age at birth is associated with poorer social functioning in adolescent males: shedding light on a core symptom of schizophrenia and autism. Schizophr Bull 34: 1042-1046.

Wijsman CA, van Heemst D, Rozing MP, Slagboom PE, Beekman M, de Craen AJ, Maier AB, Westendorp RG, Blom HJ, Mooijaart SP (2011) Homocysteine and familial longevity: the Leiden Longevity Study. PLoS One 6: e17543.

Xia RR (2011) Effectiveness of nutritional supplements for reducing symptoms in autism-spectrum disorder: a case report. J Altern Complement Med 17: 271-274. 